\section{Diagnosis of overweight and obesity in adolescents from the 1993 Pelotas Birth Cohort Study, Rio Grande do Sul State, Brazil: comparison of two diagnostic criteria}

\author{
Diagnóstico de sobrepeso e obesidade em \\ adolescentes da coorte de nascimentos de 1993 \\ de Pelotas, Rio Grande do Sul, Brasil: comparação \\ entre dois critérios de avaliação
}

Maria de Fátima Alves Vieira ${ }^{1}$

Cora Luiza Pavin Araújo ${ }^{1}$

Marilda Borges Neutzling 1

Pedro Curi Hallal 2

Ana Maria Baptista Menezes 2

\footnotetext{
${ }^{1}$ Faculdade de Nutrição, Universidade Federal de Pelotas, Pelotas, Brasil. 2 Programa de Pós-graduação em Epidemiologia, Universidade Federal de Pelotas, Pelotas, Brasil.

Correspondence M. F. A. Vieira Faculdade de Nutrição, Universidade Federal de Pelotas.

C. P. 464, Pelotas, $R S$ 96030-002, Brasil. fvieira@epidemio-ufpel.org.br
}

\begin{abstract}
Various cut-off points for body mass index have been proposed to assess nutritional status in adolescents. The aim of this study was to compare two methods for evaluating overweight and obesity. In 2004-5, 4,452 adolescents from the 1993 Pelotas (Brazil) birth cohort study were evaluated, representing $87.5 \%$ of the original cohort. Overweight and obesity were evaluated using the methods proposed by the World Health Organization (WHO) and International Obesity Task Force (IOTF). Prevalence of overweight was similar when comparing the two methods (WHO: 23.2\%; IOTF: 21.6\%). Prevalence of obesity was higher according to the WHO criterion (total sample: 11.6\%; boys: $15.1 \%$; girls: $8.2 \%$ ) as compared to IOTF (total sample: $5.0 \%$; boys: $5.6 \%$; girls: $4.4 \%$ ). The kappa statistic was around 0.9 for determining overweight and 0.4 for obesity. The IOTF classification showed high specificity in comparison to the WHO criterion for determining overweight and obesity. However, sensitivity was high for overweight but low for obesity. Our data show that the IOTF classification underestimates the prevalence of obesity in early adolescence
\end{abstract}

Body Mass Index; Overweight; Obesity; Adolescent

\section{Introduction}

The prevalence of overweight and obesity has increased alarmingly in recent years, both in developed countries and those with medium or low income. The relationship between obesity and the morbidity and mortality profile has been well established in adults. In adolescents, recent studies have shown an association between obesity and increased risk of diseases 1 . Obese adolescents are subject to discrimination and have fewer opportunities for work and social integration 2 .

Anthropometry has been the main tool for evaluating nutritional status, principally in population studies, due to its low cost and ease of use. According to World Health Organization (WHO) guidelines ${ }^{3}$, diagnosis of overweight and obesity should be done through percentiles in the body mass index (BMI) by age and gender, using the data compiled by Must et al. ${ }^{4}$. BMI values above the $85^{\text {th }}$ percentile indicate risk of overweight, as well as obesity when triceps and subscapular skinfolds greater than or equal to the $90^{\text {th }}$ percentile are also present ${ }^{3}$. The difficulty in obtaining skinfold measurements has limited the use of this criterion for classifying obesity in this age group.

An alternative method has been used frequently. The International Obesity Task Force (IOTF) recommends the use of the criterion proposed by Cole et al. 5 , in which individuals 2 to 18 years of age with BMI (by gender and age bracket) 
equivalent to BMI of 25 and 30 in adults should be classified as having overweight and obesity, respectively 5

An extensive discussion in the literature has assessed the advantages and disadvantages of each method in the correct identification of overweight and obesity prevalence. According to some studies, the IOTF 5 classification underestimates the prevalence of obesity, with variations related to gender, age bracket, ethnicity, and sexual maturation. However, the classification has been widely used in various parts of the world 6 .

The current study aims to compare overweight and obesity prevalence based on the IOTF criterion 5 in adolescents (10-12 years) from a birth cohort in the city of Pelotas, Rio Grande do Sul State, Brazil (1993) using the WHO criterion ${ }^{3}$ as the gold standard.

\section{Methodology}

In 1993, a cohort study of live in-hospital births was started in the city of Pelotas, the methodology of which has been described elsewhere 7 . A total of 5,249 life births were identified. Of these, some $20 \%$ were visited and interviewed more than once in recent years. From July 2004 to March 2005, a new follow-up was conducted in order to locate all the cohort subjects, using different strategies ${ }^{8}$.

Previously trained interviewers collected the information for the current study using household interviews with the mothers and/or guardians and the adolescents themselves. The interviews contained questions on socioeconomic, demographic, dietary, and general health conditions. The questionnaires used in this study are available on the website of the Centro de Pesquisas Epidemiológicas, Universidade Federal de Pelotas [Center for Epidemiological Research, Federal University in Pelotas] (http://www.epide mio-ufpel.org.br/_projetos_de_pesquisas/resul tado.php?id_resultado=3).

The families' socioeconomic status was assessed using the Brazilian Economic Classification ${ }^{9}$ divided into 5 levels (A, B, C, D, and E), with levels $A$ and $E$ corresponding to the families with the highest and lowest incomes, respectively. Body mass and height were measured using portable scales (SECA, Birmingham, UK), with a capacity of $150 \mathrm{~kg}$, accurate to $100 \mathrm{~g}$, and aluminum anthropometers, accurate to $1 \mathrm{~mm}$. Triceps and subscapular skinfold measurements were taken with a Cescorf caliper (Porto Alegre, Brazil) accurate to $0.1 \mathrm{~mm}$. The technique used for collecting anthropometric measurements followed the recommendations by Lohman et al. 10 .
Monthly standardization sessions were conducted to evaluate the interviewers' precision and accuracy errors. The technical errors for body mass, height, and skinfolds were considered satisfactory when they were less than or equal to those obtained by the National Center for Health Statistics (1977) when preparing the NCHS-1977 reference 11 . Quality control included repeating $10 \%$ of the household and telephone interviews, using a condensed version of the questionnaire.

The gold standard in this study to classify adolescents' nutritional status was the criterion recommended by the $\mathrm{WHO}^{3}$, which defines obesity in adolescents as $\mathrm{BMI} \geq 85^{\text {th }}$ percentile of the 1 st National Health and Nutrition and Examination Survey (NHANES I) and triceps and subscapular skinfolds $\geq$ the $90^{\text {th }}$ percentile. Risk of overweight was defined as $\mathrm{BMI} \geq 85^{\text {th }}$ percentile in NHANES I ${ }^{3}$. The current study adopted the term "overweight" when adolescents presented "risk of overweight".

In relation to the IOTF classification 5 , overweight in adolescents was defined as BMI greater than or equal to the corresponding BMI values of $25 \mathrm{~kg} / \mathrm{m}^{2}$ in adults, according to gender and age bracket. Obesity was classified as BMI values greater than or equal to BMI $30 \mathrm{~kg} / \mathrm{m}^{25}$

Data were keyed twice into Epi Info 6.0 (Centers for Disease Control and Prevention, Atlanta, U.S.A.) with automatic verification of consistency and range. The descriptive analysis included prevalence rates for overweight and obesity according to the WHO ${ }^{3}$ and Cole et al. 5 criteria, by gender, age bracket, and socioeconomic status. Kappa index was used to assess agreement between the two methods, according to the following criteria: poor agreement $(<$ $0.20)$, fair (0.21-0.40), moderate (0.41-0.60), good (0.61-0.80), and very good (>0.80) 12 . To compare the prevalence of overweight and obesity according to the IOTF 5 and WHO methods 3 , we evaluated the sensitivity, specificity, and positive and negative predictive values by gender, stratified by age bracket and socioeconomic status. $95 \%$ confidence intervals were calculated for the above-mentioned measurements.

Parents and/or guardians signed informed consent forms for the adolescents to participate in the study, which was approved by the Research Ethics Committee of the Federal University in Pelotas.

\section{Results}

Of the 5,265 live births in Pelotas in the year 1993, there were only 16 cases of refusal by parents/ guardians to participate in the original perina- 
tal study. In addition, the Mortality Information System and interviewers detected 141 deaths. Adding the deaths to the 4,452 adolescents interviewed in 2004-2005, the follow-up rate was $87.5 \%$.

Male adolescents comprised $49.3 \%$ of the total. Table 1 provides the study population's demographic, socioeconomic, and anthropometric characteristics. Approximately $80 \%$ of the sample was in the 11-11.5-year range, and nearly half belonged to economic groups D and E. Overweight prevalence rates were $23.2 \%$ and $21.6 \%$ according to the $\mathrm{WHO}^{3}$ and IOTF criteria 5 , respectively. According to the WHO criterion 3 the obesity rate was $11.6 \%$ for the total sample (15.1\% for boys and $8.2 \%$ for girls). According to the IOTF criterion 5 , the corresponding values were $5.0 \%, 5.6 \%$, and $4.4 \%$. Mean BMI was $18.6 \mathrm{~kg} / \mathrm{m}^{2}(\mathrm{SD}=3.6)$.

Tables 2 and 3 show the prevalence rates for overweight and obesity in adolescents of both genders, categorized by age bracket, and the kappa index, which assesses the agreement between two different nutritional status classification methods.

Table 2 shows very good agreement values (kappa 0.88 to 0.97 ) between the two methods for classifying overweight. As for obesity, as shown in
Table 3, the prevalence rates were always higher using the WHO criterion ${ }^{3}$, and the differences between the criteria were striking. Agreement between the two methods was considered moderate among the various age groups ( 0.41 to 0.59 ).

Tables 4 and 5 present the results for sensitivity, specificity, and positive and negative predictive values for overweight and obesity, referring to the comparison between the IOTF 5 and WHO methods 3 by gender and stratified by age bracket. Specificity was high (>98\%) for both obese and overweight adolescents. Sensitivity was only high (> 85\%) for overweight adolescents. The negative predictive values were high $(>85 \%)$ for boys and girls in all age groups. Similar results were observed for positive predictive values, except for girls 11 years or older.

\section{Discussion}

The adolescents in the current study belong to a live birth cohort from the city of Pelotas (1993) that has been monitored by studying representative samples over the course of recent years. Only the original and current follow-ups studied the total cohort. The percentage of adolescents

Demographic, socioeconomic, and anthropometric characteristics. Adolescents from 1993 Pelotas Birth Cohort Study, Rio Grande do Sul State, Brazil $(N=4,452)$.

\begin{tabular}{|c|c|c|c|c|c|c|}
\hline \multirow[t]{2}{*}{ Variables } & \multicolumn{2}{|c|}{ Male } & \multicolumn{2}{|c|}{ Female } & \multicolumn{2}{|c|}{ Total } \\
\hline & $\mathbf{n}$ & $\%$ & $\mathbf{n}$ & $\%$ & $\mathbf{n}$ & $\%$ \\
\hline \multicolumn{7}{|l|}{ Age (years) } \\
\hline 10.5 & 435 & 19.9 & 451 & 20.0 & 886 & 19.9 \\
\hline 11.0 & 1,101 & 50.3 & 1,107 & 49.0 & 2,208 & 49.6 \\
\hline 11.5 & 655 & 29.9 & 702 & 31.1 & 1,357 & 30.5 \\
\hline \multicolumn{7}{|c|}{ Socioeconomic status (ANEP) } \\
\hline$A+B$ & 452 & 20.8 & 409 & 18.3 & 861 & 19.5 \\
\hline C & 723 & 33.3 & 791 & 35.4 & 1,514 & 34.4 \\
\hline$D+E$ & 996 & 45.9 & 1,035 & 46.3 & 2,031 & 46.1 \\
\hline \multicolumn{7}{|c|}{ Nutritional status (WHO) } \\
\hline Underweight & 140 & 6.4 & 173 & 7.7 & 313 & 7.0 \\
\hline Normal & 1,497 & 68.5 & 1,603 & 71.1 & 3,100 & 69.8 \\
\hline Overweight * & 549 & 25.1 & 480 & 21.3 & 1,029 & 23.2 \\
\hline Obese & 329 & 15.1 & 186 & 8.2 & 515 & 11.6 \\
\hline \multicolumn{7}{|c|}{ Nutritional status (IOTF) } \\
\hline Normal & 1,699 & 77.7 & 1,784 & 79.1 & 3,483 & 78.4 \\
\hline Overweight ** & 487 & 22.3 & 472 & 20.9 & 959 & 21.6 \\
\hline Obese & 123 & 5.6 & 99 & 4.4 & 222 & 5.0 \\
\hline
\end{tabular}

* Overweight: includes all adolescents with body mass index (BMI) $\geq 85^{\text {th }}$ percentile;

** Overweight: includes all adolescents with $\mathrm{BMI} \geq 25$. 
Prevalence of overweight and Kappa index according to WHO 3 and IOTF 5. Adolescents from 1993 Pelotas Birth Cohort Study, Rio Grande do Sul State, Brazil $(\mathrm{N}=4,452)$

\begin{tabular}{|c|c|c|c|c|c|c|}
\hline \multirow[t]{3}{*}{ Variables } & \multicolumn{6}{|c|}{ Overweight } \\
\hline & \multicolumn{3}{|c|}{ Male } & \multicolumn{3}{|c|}{ Female } \\
\hline & $\mathrm{n}$ & $\%$ & kappa * & $n$ & $\%$ & kappa * \\
\hline \multicolumn{7}{|l|}{ Age } \\
\hline \multicolumn{7}{|l|}{10.5} \\
\hline $\mathrm{WHO}$ & 129 & 29.7 & & 115 & 25.5 & \\
\hline IOTF & 114 & 26.3 & 0.914 & 101 & 22.4 & 0.915 \\
\hline \multicolumn{7}{|l|}{11.0} \\
\hline WHO & 243 & 22.1 & & 217 & 19.6 & \\
\hline IOTF & 220 & 20.0 & 0.937 & 227 & 20.5 & 0.972 \\
\hline \multicolumn{7}{|l|}{11.5} \\
\hline WHO & 177 & 27.1 & & 148 & 21.1 & \\
\hline IOTF & 153 & 23.4 & 0.903 & 144 & 20.6 & 0.974 \\
\hline
\end{tabular}

* Kappa: assesses agreement between prevalence rates according to $\mathrm{WHO} 3$ and IOTF 5.

Prevalence of obesity and Kappa index according to WHO ${ }^{3}$ and IOTF 5. Adolescents from 1993 Pelotas Birth Cohort Study, Rio Grande do Sul State, Brazil $(\mathrm{N}=4,452)$

\begin{tabular}{|c|c|c|c|c|c|c|}
\hline \multirow[t]{3}{*}{ Variables } & \multicolumn{6}{|c|}{ Obesity } \\
\hline & \multicolumn{3}{|c|}{ Male } & \multicolumn{3}{|c|}{ Female } \\
\hline & $\mathrm{n}$ & $\%$ & kappa * & $\mathrm{n}$ & $\%$ & kappa * \\
\hline \multicolumn{7}{|l|}{ Age } \\
\hline \multicolumn{7}{|l|}{10.5} \\
\hline WHO & 83 & 19.1 & & 60 & 13.3 & \\
\hline IOTF & 26 & 6.0 & 0.425 & 20 & 4.4 & 0.411 \\
\hline \multicolumn{7}{|l|}{11.0} \\
\hline $\mathrm{WHO}$ & 143 & 13.0 & & 74 & 6.7 & \\
\hline IOTF & 51 & 4.6 & 0.491 & 46 & 4.2 & 0.543 \\
\hline \multicolumn{7}{|l|}{11.5} \\
\hline $\mathrm{WHO}$ & 103 & 15.7 & & 52 & 7.4 & \\
\hline IOTF & 46 & 7.0 & 0.532 & 33 & 4.7 & 0.588 \\
\hline
\end{tabular}

* Kappa: assesses agreement between prevalence rates according to $\mathrm{WHO} 3$ and IOTF 5.

from the original cohort interviewed in $2004-$ $2005(87.5 \%)$ deserves attention, since few cohort studies in middle or low-income countries achieve such a high follow-up rate 11 years after the beginning of a study. The representativeness of 10-12-year-old adolescents, including teenagers from all socioeconomic levels, the rigorous quality control in the interviews, and the monthly standardization of the anthropometric measurements were also positive points in the study.
Comparison of anthropometric criteria for assessing overweight and obesity in adolescents presents difficulties arising from various factors, ranging from the cutoff points adopted by each study to the lack of uniform nomenclature for defining overweight and obesity. Studies comparing internationally used classification criteria for overweight and obesity in adolescents have shown conflicting results, varying according to age bracket, gender, ethnicity, and pubertal stage 3,5 . 
Sensitivity, specificity, and positive and negative predictive values for overweight according to the IOTF 5 and WHO 3 classifications. Adolescents from 1993 Pelotas Birth Cohort Study, Rio Grande do Sul State, Brazil.

\begin{tabular}{lccccc}
\hline Variables & Age (years) & $\begin{array}{c}\text { Sensitivity } \\
\%(95 \% \mathrm{Cl})\end{array}$ & $\begin{array}{c}\text { Specificity } \\
\%(95 \% \mathrm{Cl})\end{array}$ & $\begin{array}{c}\text { PPV } \\
\%\end{array}$ & $\begin{array}{c}\text { NPV } \\
\%\end{array}$ \\
Gender & & & & \\
\hline \multirow{2}{*}{ Male } & 10.5 & $88.4(81.5-93.3)$ & $100.0(98.8-100.0)$ & 100.0 & 95.3 \\
& 11.0 & $90.5(86.1-93.9)$ & $100.0(99.6-100.0)$ & 100.0 & 97.4 \\
& 11.5 & $86.4(80.5-91.1)$ & $100.0(99.2-100.0)$ & 100.0 & 95.2 \\
Female & 10.5 & $87.8(80.4-93.2)$ & $100.0(98.9-100.0)$ & 100.0 & 96.0 \\
& 11.0 & $100.0(98.3-100.0)$ & $98.9(97.9-99.5)$ & 95.6 & 100.0 \\
& 11.5 & $96.6(92.3-98.9)$ & $99.8(99.0-100.0)$ & 99.3 & 99.1 \\
\hline
\end{tabular}

PPV: positive predictive value; NPV: negative predictive value.

Sensitivity, specificity, and positive and negative predictive values for obesity according to the IOTF 5 and WHO 3 classifications. Adolescents from 1993 Pelotas Birth Cohort Study, Rio Grande do Sul State, Brazil.

\begin{tabular}{lccccc}
\hline Variables & Age (years) & $\begin{array}{c}\text { Sensitivity } \\
\%(95 \% \mathrm{Cl})\end{array}$ & $\begin{array}{c}\text { Specificity } \\
\%(95 \% \mathrm{Cl})\end{array}$ & $\begin{array}{c}\text { PPV } \\
\%\end{array}$ & $\begin{array}{c}\text { NPV } \\
\%\end{array}$ \\
Gender & & & & \\
\hline \multirow{2}{*}{ Male } & 10.5 & $31.3(21.6-42.4)$ & $100(99.0-100.0)$ & 100.0 & 86.0 \\
& 11.0 & $35.7(27.8-44.1)$ & $100(99.6-100.0)$ & 100.0 & 91.2 \\
& 11.5 & $41.7(32.1-51.9)$ & $99.5(98.4-99.9)$ & 93.5 & 90.1 \\
Female & 10.5 & $30.0(18.8-43.2)$ & $99.5(98.2-99.9)$ & 90.0 & 90.3 \\
& 11.0 & $45.9(34.3-57.9)$ & $98.8(98.0-99.4)$ & 96.9 & 78.8 \\
\end{tabular}

PPV: positive predictive value; NPV: negative predictive value.

Prevalence rates for overweight and obesity in the current study were higher when the WHO classification method 3 was used, although the differences were only striking for obesity. These results are similar to those of Flegal et al. 13 in a study on American adolescents from the same age bracket. However, the cutoff point used in the definition of obesity by Flegal et al. 13 was greater than or equal to the WHO 95 $5^{\text {th }}$ percentile ${ }^{3}$, without including skinfold measurements. In another Brazilian study on adolescents (12-18 years) in Rio de Janeiro, Chiara et al. 14 found similar overweight prevalence rates with the two methods, a result consistent with the current study.

In the study presented here, obesity prevalence was higher in male adolescents. Similar results were found in a Brazilian study with 1516-year-old adolescents 15 . The differences in obesity prevalence between the methods were greater in boys than in girls. Flegal at al. 13 made the same observation.

Agreement was very good between the IOTF 5 and WHO 3 methods for estimating overweight prevalence, according to the kappa index in all the age groups (kappa > 0.90) and socioeconomic levels (kappa $>0.88$ ), unlike the results for classifying obesity, in which agreement became moderate between the different age groups (kappa: 0.41-0.58) and weak between the various economic groups (kappa: 0.24-0.34).

In the current study, the IOTF classification 5 showed high specificity and sensitivity for identifying adolescents at risk of overweight according to the WHO criterion 3 , for all categories. In relation to specificity, Gaskin et al. 16 showed similar results in Jamaican youth when comparing over- 
weight prevalence according to the IOTF classification ${ }^{5}$ with that found by subscapular skinfold. However, the study showed low sensitivity, classifying $25 \%$ of obese adolescents as normal (false negatives). In the current study the highest false-negative rate was $14 \%$, among upperincome boys, in whom the prevalence rate was higher.

Data obtained by Chiara et al. 14 showed low sensitivity for the IOTF method 5 as compared to skinfolds in adolescents in Niterói, Rio de Janeiro State, who were in the growth deceleration phase (40-46\%) (boys $\geq 15$ years; girls $\geq 14$ years), and $60-63 \%$ in the pre-deceleration phase. However, as in the current study, they found high specificity with the IOTF method 5, independently of the sexual maturation period. The differences observed between the studies may result from the criterion used as the gold standard, since our study used the $85^{\text {th }}$ percentile and skinfolds, while Chiara et al. 14 and Gaskin et al. 16 used only the subscapular skinfold. The choice of method to estimate the percentage of body fat is a potential source of variation in sensitivity and specificity. In the current study, we chose the method recommended by the $\mathrm{WHO} 3$.

In relation to obesity, all the data analyzed here showed high specificity, as with overweight. The proportion of adolescents without obesity according to the WHO method 3 that were classified as obese according to the IOTF method 5 was a maximum of $1.2 \%$ for all the analytical categories. However, among girls 11 years or older, the positive predictive value was 73 to $78 \%$, i.e., the probability that girls classified as obese by the IOTF method ${ }^{5}$ are truly obese is much lower than for boys.

However, the sensitivity of the IOTF method 5 for detecting obesity was very low; the proportion of obese adolescents not identified as such (false negatives) according to the IOTF method 5 varied from 50 to $70 \%$ among age brackets and from 54 to $66 \%$ among the socioeconomic levels.

A large number of false positives, i.e., normal-weight individuals classified as obese, can overload health services and waste human and material resources. Meanwhile, the high number of obese individuals classified as normal (false negatives) can delay access to health services and programs for a large contingent of adolescents, thereby jeopardizing them in the short and long term.

The IOTF method 5 dispenses with the use of skinfolds, making it more attractive for use in clinical care and simplifying nutritional assessment in this age bracket. Data from the current study suggest that utilization of the IOTF method 5 was capable of adequately identifying the risk of overweight without generating excess false positives or false negatives. However, for diagnosing obesity, this method should be used with great caution due to its low sensitivity. The current study's conclusion is that the IOTF classification is precise for assessing overweight, but that it underestimates the proportion of obese adolescents.

\section{Resumo}

Vários pontos de corte para o índice de massa corporal têm sido propostos para avaliação nutricional de adolescentes. O objetivo deste estudo foi comparar dois métodos de avaliação de sobrepeso e obesidade. Em 2004-2005, foram avaliados 4.452 adolescentes pertencentes à coorte de nascimentos de 1993 de Pelotas, Rio Grande do Sul, Brasil, representando 87,5\% da coorte original. Sobrepeso e obesidade foram avaliados segundo os métodos da Organização Mundial da Saúde (OMS) e do International Obesity Task Force (IOTF). As prevalências de sobrepeso foram semelhantes entre os métodos: OMS: 23,2\%; IOTF: 21,6\%. A obesidade foi maior com o método da OMS (amostra total: 11,6\%; meninos: 15,1\%; meninas: $8,2 \%$ ) do que com a classi- ficação IOTF (amostra total: 5\%; meninos: 5,6\%; meninas: 4,4\%). Para determinação de sobrepeso, o índice kappa foi ao redor de 0,90, enquanto na obesidade foi ao redor de 0,40. A classificação da IOTF mostrou alta especificidade em comparação à classificação da OMS para determinação de sobrepeso e obesidade. A sensibilidade foi alta para determinação de sobrepeso, mas baixa para determinação de obesidade. Os dados mostraram que a classificação IOTF subestima a prevalência de obesidade nessa faixa etária.

Índice de Massa Corporal; Sobrepeso; Obesidade; Adolescente 


\section{Contributors}

M. F. A.Vieira participated in all stages of the article. C. L. P. Araújo coordinated the fieldwork and participated in the drafting and final discussion of the article. M. B. Neutzling participated in the fieldwork and collaborated in drafting the article. P. C. Hallal coordinated the analyses, assisted in drafting the research instrument, and supervised the fieldwork. A. M. B. Menezes coordinated the fieldwork and collaborated in the final review of the article.

\section{Acknowledgments}

The following institutions funded this study: Wellcome Trust (UK), Programa de Apoio a Núcleos de Excelência [PRONEX; Brazilian National Program for Centers of Excellence] and Brazilian Ministry of Health. The initial phases of the cohort study were funded by the International Development Research Center, World Health Organization, and Overseas Development Administration (UK).

\section{References}

1. Malina RM, Katzmarzyk PT. Validity of the body mass index as an indicator of the risk and presence of overweight in adolescents. Am J Clin Nutr 1999; 70:131S-6S.

2. Gortmaker SL, Must A, Perrin JM, Sobol AM, Dietz WH. Social and economic consequences of overweight in adolescence and young adulthood. N Engl J Med 1993; 329:1008-12.

3. World Health Organization. WHO Expert Committee on Physical Status: The use and interpretation of anthropometry. Geneva: World Health Organization; 1995. (WHO Technical Series, 854).

4. Must A, Dallal GE, Dietz WH. Reference data for obesity: 85th and 95th percentiles of body mass index (wt/ht2) and triceps skinfold thickness. Am J Clin Nutr 1991; 53:839-46.

5. Cole TJ, Bellizzi MC, Flegal KM, Dietz WH. Establishing a standard definition for child overweight and obesity worldwide: international survey. BMJ 2000; 320:1240-3.

6. Neovius M, Linne Y, Barkeling B, Rossner S. Discrepancies between classification systems of childhood obesity. Obes Rev 2004; 5:105-14.

7. Victora CG, Barros FC, Tomasi E, Menezes AM, Horta BL, Weiderpass E, et al. Tendências e diferenciais na saúde materno-infantil: delineamento e metodologia das coortes de 1982 e 1993 de mães e crianças de Pelotas, Rio Grande do Sul. Cad Saúde Pública 1996; 12 Suppl 1:S7-14.

8. Victora CG, Araújo CLP, Menezes AMB, Hallal PC, Vieira MF, Neutzling MB, et al. Methodological aspects of the 1993 Pelotas (Brazil) Birth Cohort Study. Rev Saúde Pública 2006; 40:39-46.
9. Associação Nacional de Empresas de Pesquisa. Critério de classificação econômica Brasil. São Paulo: Associação Nacional de Empresas de Pesquisa; 1996.

10. Lohman T, Roche A, Martorell R. Anthropometric standardization reference manual. Champaing: Human Kinetics Books; 1988.

11. Cameron N. Reliability. In: Cameron N, editor. The measurement of human growth. London: Croom Helm; 1984. p. 100-12.

12. Altman DG. Practical statistics for medical research. London: Chapman \& Hall; 1991

13. Flegal KM, Ogden CL, Wei R, Kuczmarski RL, Johnson CL. Prevalence of overweight in US children: comparison of US growth charts from the Centers for Disease Control and Prevention with other reference values for body mass index. Am J Clin Nutr 2001; 73:1086-93.

14. Chiara V, Sichieri R, Martins PD. Sensibilidade e especificidade de classificação de sobrepeso em adolescentes, Rio de Janeiro. Rev Saúde Pública 2003; 37:226-31.

15. Monteiro POA, Victora CG, Barros FC, Tomasi E. Diagnóstico de sobrepeso em adolescentes: estudo do desempenho de diferentes critérios para o Índice de Massa Corporal. Rev Saúde Publica 2000; 34:506-13.

16. Gaskin PS, Walker SP. Obesity in a cohort of black Jamaican children as estimated by BMI and other indices of adiposity. Eur J Clin Nutr 2003; 57:420-6.

Submitted on 04/Apr/2006

Final version resubmitted on $13 / \mathrm{Feb} / 2007$

Approved on 23/Feb/2007 